\title{
Virtual Reality Fitness (VRF) for Behavior Management During the COVID-19 Pandemic: A Mediation Analysis Approach
}

\author{
Jingning Yang' \\ Rashid Menhas (D) ${ }^{2}$ \\ Jianhui Dai $\mathbb{D}^{\prime}$ \\ Tehmina Younas ${ }^{3}$ \\ Usama Anwar ${ }^{4}$ \\ Waseem |qbal ${ }^{4}$ \\ Rizwan Ahmed Laar (D) ${ }^{5}$ \\ Muhammad Muddasar Saeed ${ }^{6}$ \\ 'School of Physical Education, Soochow \\ University, Suzhou, Jiangsu Province, \\ People's Republic of China; ${ }^{2}$ Research \\ Center of Sports Social Sciences, School \\ of Physical Education and Sports, \\ Soochow University, Suzhou, Jiangsu \\ Province, People's Republic of China; \\ ${ }^{3}$ Department of Obstetrics and \\ Gynecology, Social Security Hospital \\ Gujrat, Punjab, Islamic Republic of \\ Pakistan; ${ }^{4}$ School of Energy, Soochow \\ University, Suzhou, Jiangsu Province, \\ People's Republic of China; ${ }^{5}$ College of \\ Physical Education, Hubei Normal \\ University, Huangshi, Hubei Province, \\ People's Republic of China; ' International \\ Education College Chinese and Western \\ Medicine Clinic, Dalian Medical \\ University, Dalian, Liaoning Province, \\ People's Republic of China
}

Correspondence: Rashid Menhas Research Center of Sports Social Sciences, School of Physical Education and Sports, Soochow University, Suzhou, Jiangsu Province, People's Republic of China

Email menhas.r@yahoo.com

Jianhui Dai

School of Physical Education and Sports, Soochow University, Suzhou, Jiangsu Province, People's Republic of China Email sddjh@suda.edu.cn
Background: During the COVID-19 pandemic, cellphone health apps and virtual reality fitness for treating neurological disorders such as Parkinson's were beneficial. Virtual reality has been used to treat PTSD, depression, anxieties, dementia, ADHD, dyslexia, and pain control in various settings. Virtual reality exercise has been studied for its effects on biological, mental, rehabilitation, behavior, and attitude management.

Purpose: This research aimed to find out the role of virtual reality fitness (VRF) for behavior management during the COVID-19 pandemic concerning the demographic characteristics of the study participants and the use of fitness and health apps.

Methods: The population for the current study was Chinese residents across China who were in home isolation during the early pandemic in China. According to the study objective, a convenience sampling method was used to collect the primary data through an online survey. SPSS-25 statistical software was used to analyze the demographic information and clean and prepare the data to test all proposed hypotheses. The proposed research framework was examined using the structural equation modeling (SEM) approach through SmartPLS 3.0 software.

Results: The structural equation model analysis shows that all the proposed hypotheses $(\mathrm{H} 1$ : $\beta=0.137, \mathrm{t}=10.454, \mathrm{p}=<0.000 ; \mathrm{H} 2: \beta=0.256, \mathrm{t}=16.824, \mathrm{p}=<0.000 ; \mathrm{H} 3: \beta=0.418, \mathrm{t}=$ 27.827, $\mathrm{p}=<0.000$; H4: $\beta=0.133, \mathrm{t}=8.913, \mathrm{p}=<0.000$; H5: $\beta=0.076, \mathrm{t}=4.717, \mathrm{p}=$ $<0.000$; H6: $\beta=0.162, \mathrm{t}=10.532, \mathrm{p}=<0.000 ; \mathrm{H} 7: \beta=0.384, \mathrm{t}=26.645, \mathrm{p}=<0.000)$ are confirmed.

Conclusion: Fitness and health apps with virtual reality fitness play a substantial role in improving the overall quality of life and positively influencing behavior and attitude.

Keywords: COVID-19, virtual reality fitness, demographic status, fitness and health apps, behavior and attitude

\section{Introduction}

The Cambridge Dictionary defines virtual reality (VR) as "a combination of visuals and audio computer - generated that appear to depict a location or a scenario in which a human can participate ${ }^{1,}$. Virtual reality applications have been created for various objectives, including pleasure, learning, commerce, and medical. Virtual reality has been employed to promote mental wellbeing in various settings. Stress, fears, shock, anorexia nervosa, alcohol misuse, social phobia, post-traumatic anxiety, dementia, chronic depression, psychotic, despair, and dyslexia have all been successfully treated with VR-based techniques, according to recent studies., ${ }^{2,3}$ Electronic media's reducing prices and expanding ease and strength are causing 
a transformation in medicine, and technological advances are influencing how we give and get treatment. In an empirically based atmosphere, virtual reality can be used to test neural correlates, feelings, and actions. The detailed presentation and monitoring of continuous visual inputs underpin VR's accuracy. Furthermore, virtual worlds can deliver precise estimation by simulating circumstances that blend the safety of experimental data with the realism of everyday life. ${ }^{4}$ People may experience a great deal of embodiment (the emotional experience of "being in it") in interactive virtual scenarios, another key added advantage of virtual reality. ${ }^{5}$

Virtual reality allows for modifying the surroundings, which can modify the ambient factors that cause discomfort in individuals with mental illnesses, promoting learning to manage their issues6 effectively. ${ }^{6}$ In treating depressive illnesses, virtual reality therapy is becoming more common. Conversely, the minimal study has been conducted on the effects of virtual training on stress and depressed behaviors. Virtually training helps relieve anxious and depression-related feelings. Positive benefits, such as vitality and pleasure, rose after virtual reality training, while detrimental consequences (such as exhaustion and stress) decreased. ${ }^{7}$ Children undergoing surgery might benefit from an immersive virtual game to simulate a preparatory operation. The kids in the virtual reality enrichment group played a five-minute game. They witnessed the surgical treatment and an aesthetic initiation in a digital world one hour before entering the surgery theatre. The results showed that students in the gaming group had much fewer anxiety symptoms than the control subjects. Furthermore, children in the stimulation condition had a clause during an aesthetic initiation. The full impact of gaming and virtual reality immersion helped decrease stress in pediatric patients. ${ }^{8}$

Conventional psychological therapies have lately been changed to digital or telemedicine versions to increase access to psychological services. ${ }^{9}$ Online psychological self-help therapies can be delivered anywhere, removing logistical and geographical limitations to care delivery. Consequently, they are frequently less costly and time-consuming than traditional treatments, resulting in a reduced burden on the health system and considerable improvements in identity procedures. Virtual reality also plays a vital role in the e-rehabilitation of various diseases patients such as Parkinson disease (PD) ${ }^{10-13 .}$ Virtual reality (VR) in interactive computer games and exergaming can be utilized as a supplement to traditional therapy methods. Virtual reality activities could be used as a supplement to traditional activities to improve joint mobility and neuroplasticity. Virtual reality-based activities could help people improve their motor skills by mixing physical and cognitive instruction in a pleasant and engaging way. ${ }^{14} \mathrm{WHO}$ announced several preventive measures for active living during the isolation period of the COVID-19, including physical exercise, health monitoring, wearing a mask, frequently washing hands, and avoiding unnecessary travel. ${ }^{15,16}$ Covid-19 impacts people's emotional and physical health and an elevated factor of loneliness in their lives due to a lack of interaction with other social beings. They also mention how digital technology reduces lockdown loneliness; various online technologies have been employed in pandemics to keep the globe running. More technologies and social applications are being developed during the epidemic to combat loneliness. The employment of these technologies has both positive and negative aspects. Many people lack sufficient knowledge and access to digital technology, necessitating action by providing them with skills and access. ${ }^{17,18}$

\section{COVID-19 and Psychological Health}

Multiple researchers have discovered a high incidence of disease outbreak depressive symptomatology and mental trauma due to this outbreak. ${ }^{19}$ The higher incidence of worry and pressure diseases could be entirely due to the outbreak, such as anxieties of contracting the virus or generalized feelings of uncertainty. ${ }^{20}$ According to a metaanalysis of prior coronavirus illnesses, a negative state, panic, disorientation, and decreased cognition were usual signs of the active infection of past coronavirus illnesses. Patients should heal from mental conditions without suffering mental illness if SARS-CoV-2 follows the same path as earlier coronaviruses. ${ }^{21}$ Anxiety is a psychiatric illness marked by anxious thoughts, tense feelings, and body effects, including elevated blood pressure. ${ }^{22}$ Home quarantine due to restrictions and lockdown measures has been connected to feelings of insecurity about the future and a fear of new and undiscovered infectious agents, culminating in excessively high anxiousness. ${ }^{23}$ Furthermore, stress is linked to weariness and poor performance among healthcare workers, but boredom and loneliness are linked to rage, irritation, and bearing the brunt of confinement constraints. ${ }^{24}$ The sociopsychological effects of the COVID-19 pandemic have been revealed now. If not treated promptly and adequately with appropriate evidence-based interventions, it might have longterm negative health effects. ${ }^{25}$ Virtual reality fitness therapy has significant positive impacts on wellbeing. The impact of 
virtual reality-based therapies on anxiety concentrates primarily on virtual reality training, with virtual reality workouts in treating chronic diseases receiving little attention. Virtual reality training involves the addition of virtual reality abilities to conventional workout equipment such as bicycles and treadmills. Specifically, some new fitness machines include incorporated detectors that synchronize with a PC or games system, allowing players to participate in strenuous physical effort on the machine while also playing virtual reality games. Virtual reality combined with workout equipment (a.k.a. virtual reality fitness) has been shown to improve the psychological advantages of activity and raise the likelihood of lengthy commitment to exercise by workers and health experts. ${ }^{26}$ The trend of using fitness and health apps increased among the Chinese during the COVID-19 pandemic compared to before the COVID-19 pandemic (46.18\% February 2019 and 89.28\% February 2020). ${ }^{27}$ Patients who have conquered COVID-19 may benefit from virtual reality for physical rehabilitation and psychological assistance. $^{28}$

\section{Statement of the Study}

Isolation is unusual among those who participate in social activities, and socially active people have better physical health than those who do not. ${ }^{29}$ During the COVID-19 pandemic, the computer revolution has unquestionably become essential for lowering and mitigating communal, medical, and emotional dangers and managing the brief and long influence of social separation and lockdown isolation. ${ }^{30} \mathrm{By}$ incorporating gaming into eHealth systems, health records and behavioral changes can be made more engaging and fun. ${ }^{31}$ Virtual reality has been used to treat PTSD, depression, anxieties, dementia, ADHD, dyslexia, and pain control in various settings. ${ }^{32}$ Virtual reality exercise has been studied for its effects on biological, mental, and rehabilitative results. Virtual reality, for instance, has been suggested as a way to improve the lower extremity purpose of stroke victims. ${ }^{33}$ Virtual reality exercise has also been demonstrated to improve the balance skills of stroke patients, Parkinson's diabetics, and youngsters with downs syndrome. ${ }^{34}$ Anxiety and depression can be treated with various approaches, including medications, activity, mindfulness, and cognitivebehavioral therapy. This research aimed to find out the role of virtual reality fitness (VRF) for behavior management during the COVID-19 pandemic concerning the demographic characteristics of the study participants and the use of fitness and health apps. Figure 1 shows the proposed relationship of the study variables and hypotheses are given below;

\section{Study Hypotheses}

H1: Gender has a positive association with the use of virtual reality fitness during the COVID-19 lockdown

H2: Age has a positive association with the use of virtual reality fitness during the COVID-19 lockdown

H3: Education has a positive association with the use of virtual reality fitness during the COVID-19 lockdown

H4: Occupation has a positive association with the use of virtual reality fitness during the COVID-19 lockdown

H5: Marital status has a positive association with the use of virtual reality fitness during the COVID-19 lockdown

H6: The use of fitness and health apps has a significant impact on behavior and attitude management during the COVID-19 lockdown

H7: The use of virtual reality fitness has significant impacts on behavior and attitude management during the COVID-19 lockdown

\section{Materials and Methods}

The current study was conducted in China and was exploratory in nature. The study adhered to the World Medical Helsinki Policy's principles. Soochow University's Ethical Committee in Suzhou, Jiangsu, approved the study before the final data collection. The participant's participation in the study was voluntary, and informed consent was taken from the study participants prior to the study commencement.

\section{Study Design}

A convenience sampling technique was used for the collection the primary data. A population-based online cross-sectional survey (https://www.wjx.cn/index.aspx) was conducted between January and March 2020. Before conducting the final survey, a pre-testing was done on 75 respondents to assess the response rate. Some questions were modified after pre-testing to get the best response rate. After the data quality check, 4300 participants' responses were considered.

\section{Survey Measures}

The primary data was collected using a well-designed questionnaire. The questionnaire was based upon closeended, open-ended, and Likert scale questions.

\section{Demographic Information}

Demographic questions were related to gender (male, female), age (18-19, 20-29, 30-39, 40-49, 50-59, $60+$ years old), education (primary school, middle school, high school, technical and vocational college graduate, university 


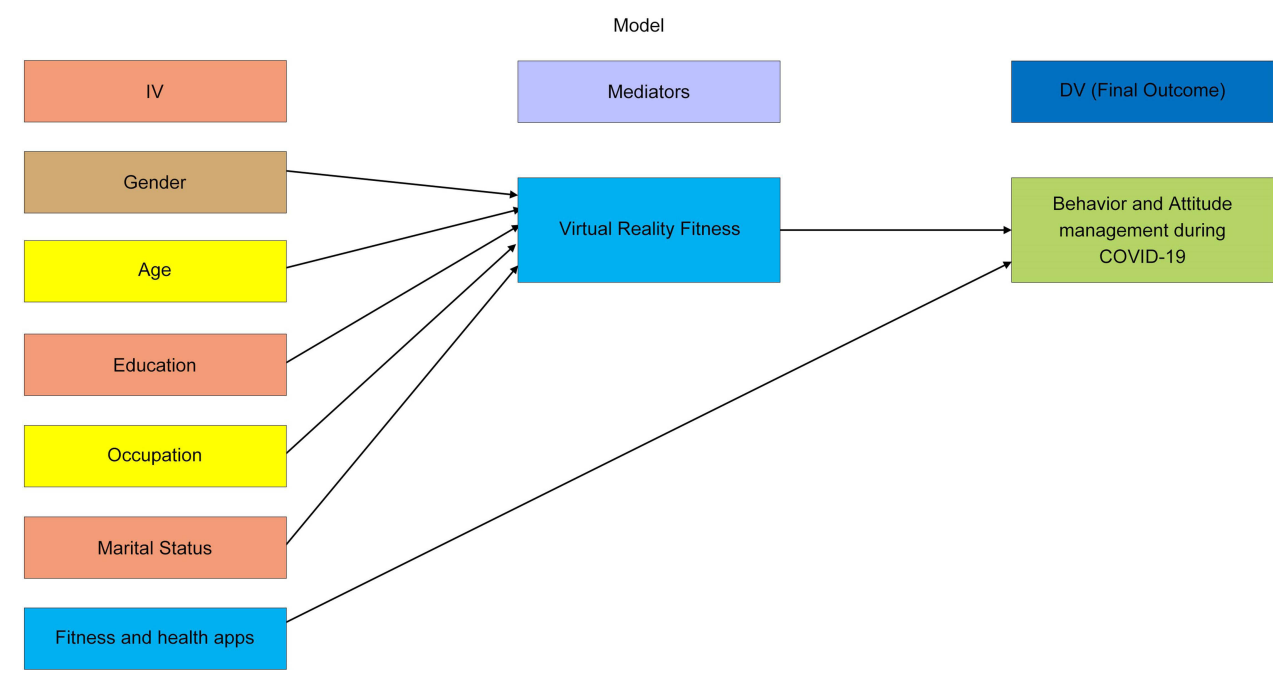

Figure I Proposed Hypotheses of the Study Conceptual Framework.

graduate, and others) and occupation (self-employed, private companies employees, government employee, student and others).

\section{Fitness and Health Apps}

Physical activity is a natural medicine against different diseases and makes the human body's immune system strong. WHO announced particular guidelines for physical activity during the lockdown period for staying active at home. ${ }^{35}$ Physical activity-related questions were about participation in physical activity (never, rarely, sometimes, often and always), frequency of physical activity during the COVID-19 lockdown (less than once a week, one time or more per week, every day), the place for physical activity during the COVID-19 lockdown (outdoor (in house lawns), indoor (in the room of the house) and others), duration of physical activity during the COVID19 lockdown (less than 30 minutes, 30 to 60 minutes and 60 minutes or more) and the primary purpose of physical activity using fitness apps (anaerobic exercise, aerobic training, running and cardio fitness).

\section{Virtual Reality Fitness (VRF) for Behavior and Attitude Management During the COVID-19}

Immersive, non-immersive, and interactive virtual reality are the three varieties of virtual reality. Immersive virtual reality uses face showcases, muscle motion sensors, actual visuals, and sophisticated interface devices (eg, devoted earphones) to make an entirely virtual environment for the user. In contrast, non-immersive virtual reality uses a big- screen TV display and needs a correlating keypad, gamepad, and gamepad. ${ }^{7}$ In terms of behavior change tactics, an examination of popular applications found that most app descriptions detailed no more than four. ${ }^{31}$ Some fitness technology initiatives for behavior change are beneficial, despite a lack of theory and behavior change procedures. Technology that tracks behavior over time and displays the user's behavior trends in a visual format, for example, has been demonstrated to have a favorable impact on health behavior. ${ }^{36}$ Virtual reality fitness for behavior and attitude management during the COVID-19 questions (The use of fitness and health apps are positively influencing the behavior and attitude during the COVID-19 isolation; Virtual reality fitness is helpful to maintain psychological wellbeing; Virtual reality fitness is beneficial in healthy and active living and the use of virtual reality fitness influence the behavior and attitude positively during the COVID-19) were asked to assess the role of virtual reality fitness for behavior and attitude among the study participants in relation with demographic information.

\section{Data Analysis}

SPSS-25 statistical software was used to present descriptive statistics of the study participants related to their demographic information (N-4300). The proposed research framework was examined using the structural equation modeling (SEM) approach for this work, and the SEM approach was employed through SmartPLS 3.0 software. SEM technique using partial least squares (PLS) was chosen in preferences for constructs and indicators. ${ }^{37}$ The SEM technique is used to measure the model 
assessment through discriminant and convergent validity and calculate average variance extracted values for each construct using factor loadings. Therefore, it is a multivariate analysis method to analyze the multiple relationships between variables of the conceptual model.

\section{Results}

\section{Descriptive Statistics}

Table 1 statistics show that most of the study participants $(51.04 \%)$ were female and (48.95\%) were male. Age distribution shows that majority of the study participants were 20-29(40.72\%), 30-39(25.23\%), 40-49 (19.0\%), $18-19(10.53 \%)$ and $60+(4.74 \%)$ old. The educational division shows that a major proportion of the study participants were university graduates $(30.58 \%)$, technical and vocational college graduates (26.49\%), high school (23.81\%), middle school (9.62\%), others $(4.77 \%)$, and primary school $(4.72 \%)$. Occupation statistics show that the majority of the respondents were private companies employees $(41.77 \%)$, students (19.79\%), self-employed (17.42\%), government employees $(12.77 \%)$, no occupation $(6.98 \%)$, retired $(0.95 \%)$, and others $(0.32 \%)$. Marital division shows that a major proportion of the study participants were married $(62.95 \%)$ while $(34.60 \%)$ were unmarried and $(2.44 \%)$ others.

\section{Multivariate Analysis}

\section{Measurement of the Research Framework}

Cronbach alpha values were used to assess the reliability of the factors and questions included in the online survey. Cronbach alpha values calculated were $0.930,1,1,1,1,1$, 0.937 , and 0.934. (See Table 2). According to Nunnally ${ }^{38}$ above 0.70 document the standardized value of Cronbach alpha for measuring the reliability. According to the standard, each factor's Cronbach alpha is considered reliable. Confirmatory factor analysis (CFA) was used to determine the study model's convergent and discriminant validity. According to Campbell \& Fiske, ${ }^{39}$ construct validity is grounded on the multitrait-multimethod matrix used to assess convergent techniques. The composite reliability (CR) standard range value is higher than 0.70. Each construct CR values were estimated as $0.950,1,1,1,1,1,0.955$ and 0.953 . Factor loading levels were consistently over the 0.60 criterion in this study. The standard range of average variance extracted is 0.50 . The AVE values of this work are $0.826,1,1,1,1,1,0.841$, and 0.836 , which are higher
Table I Background Information of the Study Participants (N-4300)

\begin{tabular}{|c|c|c|}
\hline Variables & Categorization & $\begin{array}{l}\text { Frequencyl } \\
\text { Percentage }\end{array}$ \\
\hline \multirow[t]{2}{*}{ Gender } & Male & $2105(48.95 \%)$ \\
\hline & Female & $2195(51.04 \%)$ \\
\hline \multirow[t]{6}{*}{ Age } & $18-19$ & $453(10.53 \%)$ \\
\hline & $20-29$ & $|75|(40.72 \%)$ \\
\hline & $30-39$ & $1085(25.23 \%)$ \\
\hline & $40-49$ & 437 (19.0\%) \\
\hline & $50-59$ & $370(8.60 \%)$ \\
\hline & $60+$ & $204(4.74 \%)$ \\
\hline \multirow[t]{6}{*}{ Education } & Primary School & $203(4.72 \%)$ \\
\hline & Middle School & $414(9.62 \%)$ \\
\hline & High School & $1024(23.81 \%)$ \\
\hline & $\begin{array}{c}\text { Technical and Vocational College } \\
\text { Graduate }\end{array}$ & II 39 (26.49\%) \\
\hline & University Graduate & 1315 (30.58\%) \\
\hline & Others & 205 (4.77\%) \\
\hline \multirow[t]{7}{*}{ Occupation } & Self-employed & 749 (17.42\%) \\
\hline & Private Companies Employee & 1796 (4I.77\%) \\
\hline & Government Employee & $549(12.77 \%)$ \\
\hline & Student & 851 (19.79\%) \\
\hline & Retired & $4 \mathrm{I}(0.95 \%)$ \\
\hline & No occupation & $300(6.98 \%)$ \\
\hline & Others & $14(0.32 \%)$ \\
\hline \multirow{3}{*}{$\begin{array}{l}\text { Marital } \\
\text { Status }\end{array}$} & Married & $2707(62.95 \%)$ \\
\hline & Unmarried(single) & $1488(34.60 \%)$ \\
\hline & Others & $105(2.44 \%)$ \\
\hline
\end{tabular}

than the usual range. Discriminant validity was used to measure and describe constructs that were not theoretically related to one another. Additionally, discriminant validation provides proof of all measurements about the dissimilarity of all components. Discriminant validity involves a statistical evaluation of not statistically connected components to other factors when determining the correspondence of measures. The correlation between constructs and the Square Root of AVE values of a factor can be used to 
Table 2 Display the Measurement of Research Model with Convergent Validity (N-4300)

\begin{tabular}{|c|c|c|c|c|c|c|}
\hline Constructs & Items & Loadings & VIF & $\mathbf{C} \alpha$ & SCR & AVE \\
\hline \multirow[t]{4}{*}{ Behavior and Attitude Management } & BAMI & 0.904 & 3.178 & \multirow[t]{4}{*}{0.930} & \multirow[t]{4}{*}{0.950} & \multirow[t]{4}{*}{0.826} \\
\hline & BAM2 & 0.914 & 3.451 & & & \\
\hline & BAM3 & 0.908 & 3.291 & & & \\
\hline & BAM4 & 0.911 & 3.379 & & & \\
\hline Gender & DII & 1.000 & 1.000 & 1.000 & 1.000 & 1.000 \\
\hline Age & DI2 & 1.000 & 1.000 & 1.000 & 1.000 & 1.000 \\
\hline Education & DI3 & 1.000 & 1.000 & 1.000 & 1.000 & 1.000 \\
\hline Occupation & DI4 & 1.000 & 1.000 & 1.000 & 1.000 & 1.000 \\
\hline Marital Status & DI5 & 1.000 & 1.000 & 1.000 & 1.000 & 1.000 \\
\hline \multirow[t]{4}{*}{ Fitness and health Apps } & FHAI & 0.944 & 5.031 & \multirow[t]{4}{*}{0.937} & \multirow[t]{4}{*}{0.955} & \multirow[t]{4}{*}{0.841} \\
\hline & $\mathrm{FHA} 2$ & 0.911 & 3.547 & & & \\
\hline & FHA3 & 0.902 & 3.201 & & & \\
\hline & FHA4 & 0.910 & 3.462 & & & \\
\hline \multirow[t]{4}{*}{ Virtual Reality Fitness } & VRFI & 0.910 & 3.377 & \multirow[t]{4}{*}{0.934} & \multirow[t]{4}{*}{0.953} & \multirow[t]{4}{*}{0.836} \\
\hline & VRF2 & 0.915 & 3.527 & & & \\
\hline & VRF3 & 0.916 & 3.613 & & & \\
\hline & VRF4 & 0.916 & 3.519 & & & \\
\hline
\end{tabular}

Table 3 Display Discriminant Validity Analysis (N-4300)

\begin{tabular}{|l|l|l|l|l|l|l|l|l|}
\hline Constructs & Age & BAM & Education & FHA & Gender & Marital Status & Occupation & VRF \\
\hline Age & 1.000 & & & & & & \\
\hline BAM & 0.292 & 0.909 & & & & & & \\
\hline Education & 0.257 & 0.413 & 1.000 & & & & \\
\hline FHA & 0.334 & 0.575 & 0.443 & 0.917 & & & & \\
\hline Gender & 0.376 & 0.356 & 0.342 & 0.356 & 1.000 & & & \\
\hline Marital Status & 0.268 & 0.345 & 0.417 & 0.351 & 0.409 & 1.000 & & \\
\hline Occupation & 0.392 & 0.396 & 0.510 & 0.432 & 0.433 & 0.630 & 1.000 & \\
\hline VRF & 0.337 & 0.555 & 0.451 & 0.410 & 0.373 & 0.375 & 0.451 & 0.914 \\
\hline
\end{tabular}

Abbreviations: BAM, Behavior and attitude management; FHA, Fitness and health apps; VRF, Virtual reality fitness.

determine DV. The correlation between constructs and the Square Root of AVE values of a factor can be used to determine DV. The square root of the AVE values should be used to calculate correlations. According to the DV analysis (see Table 3), all square roots of AVEs are higher than correlation values, indicating a favorable evaluation.
The multicollinearity of all elements was also examined using the variation influence factor (VIF) value. VIF must be less than ten, and a number of five is considered satisfactory. The VIF values for all formative constructs in this study are less than 5 , indicating that multicollinearity is not an issue. 
Table 4 Model Fit Summary (N-4300)

\begin{tabular}{|l|c|}
\hline Statistical Tests & Estimated Model \\
\hline SRMR & 0.041 \\
\hline d_ULS & 0.258 \\
\hline d_G & 0.069 \\
\hline Chi-Square & 1702.878 \\
\hline NFI & 0.969 \\
\hline
\end{tabular}

Abbreviations: SRMR, standardized-root-mean-square-residual; d_ULS, unweighted least squares discrepancy; d_G, geodesic discrepancy; NFI, normed fit index.

\section{Structural Equation Model}

The current study used structural equation modeling to examine all of the hypotheses offered (SEM). The SEM technique was implemented using the smart-PLS 3.3.0 package. This study's model fitness used the standardizedroot-mean-square-residual (SRMR), chi-square, and normed fit index (NFI). Model fitness is determined using the SRMR value, a standardized-residuals index by comparing observed covariance and hypothesized matrices. A range of SRMR values of 0.08 or less can be employed. According to the results, the estimated SRMR value is 0.041 , which is acceptable as a good model fit. The NFI value is 0.969 , and chi-square $\left(\chi^{2}\right)$ shows the value of 1702.878 , as shown in Table 4.

The significance level of the presented hypotheses was determined using the standard beta. The beta value demonstrates how individual variables might differ from one another. Each relationship's standardized beta $(\beta)$ value was determined according to the hypothesized study model (see Table 5). The significant impacts of endogenous latent variables will be considered high if beta $(\beta)$ values are high and significant. T-statistics were also utilized to check the relevance of each path's beta value. The beta $(\beta)$ value was obtained using the bootstrapping technique, which was used to determine the relevance of proposed links and analyze and evaluate their significance. Table 5 andFigure 2 show this work's proposed structural model relationships and $(\beta)$ statistics. Figure 3 shows the smartPLS-bootstrapping $t$-values of the study variables.

The results for $(\mathrm{H} 1: \beta=0.137, \mathrm{t}=10.454, \mathrm{p}=<0.000$; $\mathrm{H} 2: \beta=0.256, \mathrm{t}=16.824, \mathrm{p}=<0.000$ ) statistically reveals that age and education has a significant positive impact on VRF. H3 results $(\beta=0.418, \mathrm{t}=27.827, \mathrm{p}=<0.000)$ proved that fitness and health apps have a significant positive impact on BAM. The results for $\mathrm{H} 4$ statistically document that gender reveals a significant positive impact on VRF. According to results, H4 is supported with ( $\beta=$ $0.133, \mathrm{t}=8.913, \mathrm{p}=<0.000)$ which claimed a positive association between gender and VRF. The results for H5 statistically document that marital status reveals a significant positive impact on VRF. According to results, H5 is supported with $(\beta=0.076, t=4.717, p=<0.000)$, which claimed a positive association between marital status and VRF. The results for H6 statistically document that occupation reveals a significant positive impact on virtual reality fitness. According to results, $\mathrm{H} 6$ is supported with $(\beta=0.162, \mathrm{t}=10.532, \mathrm{p}=<0.000)$ which claimed a positive association between occupation and VRF. The results for $\mathrm{H} 7$ statistically document that virtual reality fitness reveals a significant positive impact on BAM. According to results, H7 is supported with $(\beta=0.384$, $\mathrm{t}=26.645, \mathrm{p}=<0.000)$ which claimed a positive association between VRF and BAM.

Table 5 Final Results for Standard Beta, T-Statistics and P-values (N-4300)

\begin{tabular}{|l|c|c|c|c|}
\hline Hypothesis's & Std. Beta $(\boldsymbol{\beta})$ & T-Statistics & P-values & Decision \\
\hline Age -> VRF & 0.137 & 10.454 & 0.000 & Confirmed \\
\hline Education -> VRF & 0.256 & 16.824 & 0.000 & Confirmed \\
\hline Fitness and health Apps -> BAM & 0.418 & 27.827 & 0.000 & Confirmed \\
\hline Gender -> VRF & 0.133 & 8.913 & 0.000 & Confirmed \\
\hline Marital Status -> VRF & 0.076 & 4.717 & 0.000 & 0.000 \\
\hline Occupation -> VRF & 0.162 & 10.532 & 0.000 & Confirmed \\
\hline Virtual Reality Fitness -> BAM & 0.384 & 26.645 & Confirmed \\
\hline
\end{tabular}

Abbreviations: VRF, Virtual reality fitness; BAM, Behavior and attitude. 


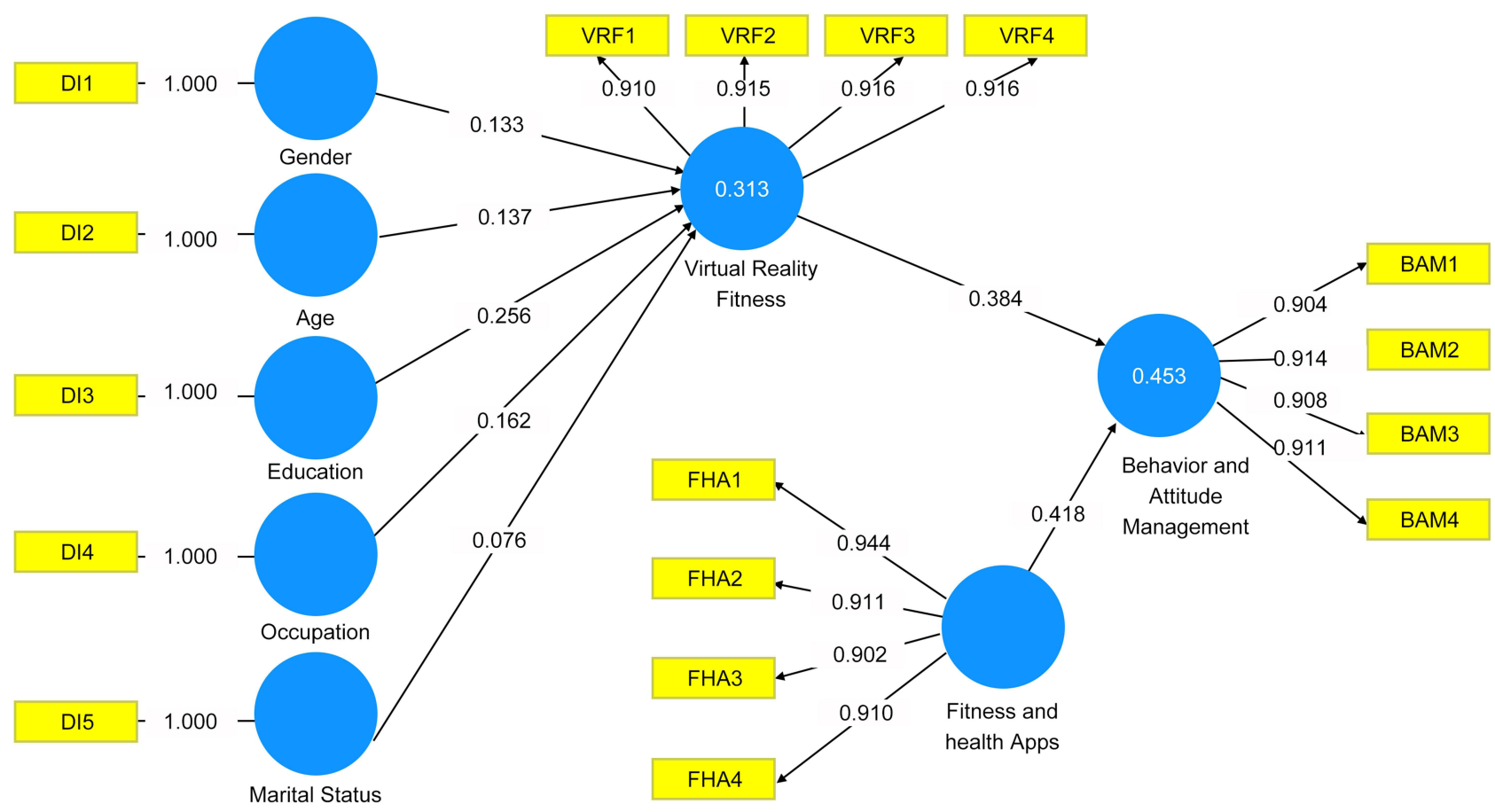

Figure 2 SmartPLS SEM Results.

\section{Discussion}

As a tool for treating, virtual reality treatment enables individuals to amplify repetitive work and increase vision and hearing input, more exciting than traditional physical therapy while posing no serious threat or physical issues. ${ }^{40}$ Virtual reality fitness therapies can be adjusted to the clients' needs to reduce anxiety and sadness symptoms in many circumstances. Until now, developing technologies in health promotion have piqued the public's curiosity. Virtual reality is undoubtedly the most exciting and technically sophisticated of the new technologies that could potentially aid in the therapy of anxiety. ${ }^{41}$ More extended quarantine periods have been linked to poor mental health, including traumatic stress. Quarantine length is a significant factor of stress. Persons who have been in confinement for more than one week have demonstrated substantially more comment psychological stress than those who have been in confinement for less than ten days. ${ }^{42}$ Growing virtual reality fitness features may help steer users toward more ideal emotions even when they are not actively managing their emotional states. ${ }^{43}$ Our study results show that VRF and various demographic factors include age, education, gender, marital status, and occupation. The intention and influence of using technology for different socio-psychological and health issues are based on various factors such as performance and perceived usefulness. These factors with demographic paradigm shape our attitude towards the use of technology such as VRF and mHealth apps for health wellbeing. ${ }^{44}$ "People of all ages have been affected by the COVID-19 lockdown around the world. Strain, despair, impatience, restlessness, panic, perplexity, rage, irritation, and apathy have increased due to isolation and stress. Individuals, who have used VR technology during lockdown to relax, exercise more enthusiastically, and have a better outlook on life. $^{45}$

According to the latest theory of human essentials in COVID-19 detention, unfamiliarity emphasizes several conditions, including satiating immediate physical needs, as well as the need for identity, affiliation, and social position; as a result, fear, anxiety, and frustration are all negative mental health consequences, and people are more likely to develop depression as a result. ${ }^{46}$ The mechanisms of how to persuade others to modify their behavior are explained by social cognitive theory. It implies that people do not need to try a new activity on their own; instead, we learn through watching others, with the environment, behavior, and individual thinking as of primary influences on the learning experience. When people watch a model do a task, they remember the outcome and use it to influence subsequent actions. ${ }^{47}$ The findings of our study are according to prior research and show that fitness and 


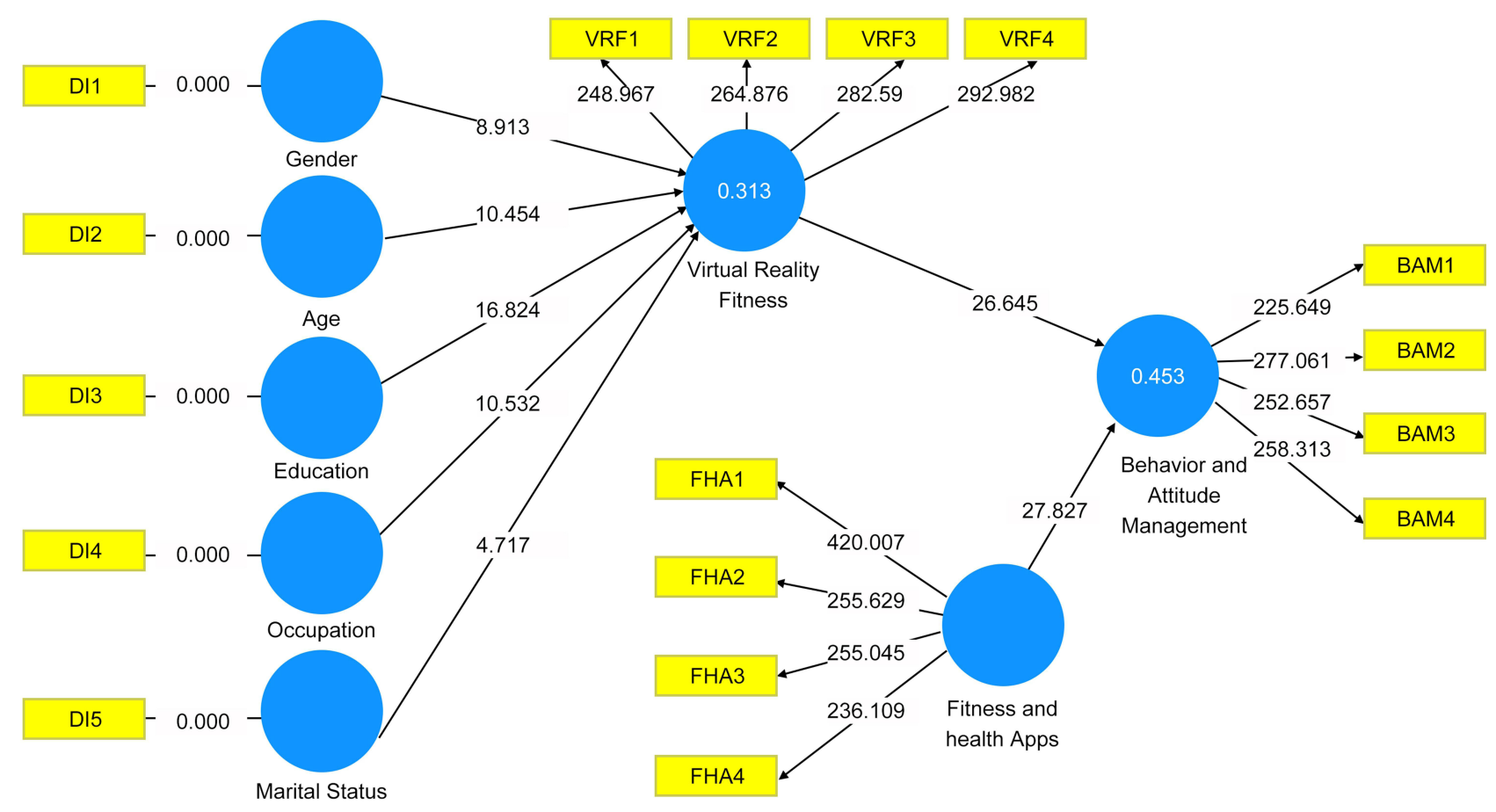

Figure 3 PLS-bootstrapping T-values.

health apps positively impact attitude and behavior through physical exercise. The use of health and fitness apps for physical activity and wellbeing increased during the COVID-19 pandemic isolation. Exercise is a natural medicine for the human body to improve sociopsychological and physical health wellbeing. According to biological theories, exercise boosts the body's temperature, endocrine, and corticosteroid function and stimulates the release of certain transmitters like endorphins, according to biological theories. ${ }^{48}$ Acute aerobic workouts are demonstrated to help reduce ego stress from anxious lab stimuli in men, and state anxiety was decreased dramatically in adult males immediately after a 20 -minute exercise session which is further helpful in behavior and attitude management. ${ }^{49}$ Various studies results indicate that interventions for psychological health management are using VRF techniques effectively to treat autism, anxiety, depression, stress, bipolar disorder, substance abuse, schizophrenia, and panic disorders. ${ }^{2,3}$ VRF is the best technique for the self-management of mental and behavioral health. Anxiety and depression in the mental health paradigm are the most common disorders worldwide, which can be effectively managed through VRF. ${ }^{50,51}$

Virtual reality is a new technology that allows us to investigate ways to better engage people with health messaging and employ this novel method to promote healthy behaviors and advance new theories. Immersive surroundings technology replaces sensory information we receive in the real world with 3-dimensional views of the simulated space, rational responses, and real-time synchronization of one's behaviors to create engaging, credible, and carefully regulated worlds that seem real to the users. As an advanced type of human interaction, virtual reality allows people to engage with and immerse themselves in PC virtual environments, allowing them to have a completely new physiological, mental, and social revolution. Virtual reality allows consumers to receive medical therapies or instruction as actively participating in an elevated, dynamic, and individualized virtual world, rather than as inert spectators. ${ }^{52}$ Statistical findings of our study reported that virtual reality fitness has a positive role in behavior and attitude management during the COVID-19 pandemic isolation. Similar results reported in many studies and state that virtual reality exercise has been acknowledged as a new way to encourage strength training and healthy behaviors in recent years. It is now being utilized more frequently in health promotion. Virtual reality fitness has been shown to improve the psychological effects of exercise and raise the likelihood of lengthy exercise adherence. ${ }^{53}$ Virtual reality has expanded the spectrum of psychological treatment, for example, in treating phobias. ${ }^{54}$ COVID-19 related psychiatric anguish 
affects a particular demographic group specifically and the interrupted psycho-social or mental health services due to the COVID-19 lockdown. ${ }^{55}$ A personalized avatar in VR is a unique feature that significantly impacts psychological health. Users can communicate with other users in realtime in virtual worlds, which are represented by personalized avatars. Avatar therapy through VRF can be helpful to maintain positive behavior during the stressful time of the COVID-19. VRET has grown in popularity as a treatment for anxiety and depression, with a growing body of evidence indicating that it is a beneficial technique for managing panic and stress symptoms. ${ }^{56}$

\section{Conclusion}

Virtual reality fitness is a relatively new technology that can be used to connect with fitness. The user is engaged in a world that displays and simulates helpful, familiar, or novel visual/auditory stimuli, which is why virtual reality is used in conjunction with exercising. Virtual reality applications have been created for various objectives, including pleasure, entertainment, commerce, and medical. In a variety of settings, virtual reality has been utilized to benefit users' mental health. Anxiety, phobias, stress, eating disorders, substance misuse, severe anxiety, comment stress disorder, schizophrenic, chronic depression, insanity, sadness, and autistic have all been treated successfully with VR-based techniques. The COVID-19 pandemic impacted human beings' socio-economic and psychological wellbeing negatively. The negative impacts of the COVID-19 pandemic also have drastic effects on isolated people's behavior and attitude. Fitness and health apps with virtual reality fitness play a significant role in improving the overall quality of life and positively influencing behavior and attitude. Virtual reality fitness, mixed reality (AR), and computer games (VGs) appear to be some of the most attractive technology solutions for combating COVID-19's mental health effects. VRF is the latest intervention to promote overall psychological wellbeing and VR fitness prescribing supplements or replacing traditional psychiatric care.

\section{Limitations and Future Scope of the Study}

The population for the current study was Chinese residents ( +18 years old) across China who were in home isolation during the early pandemic in China and used virtual reality fitness (VRF) for behavior and attitude management.
According to the study's purpose and nature, under the non-probability sampling (NPS) strategy, the convenience sampling approach was adopted for the data collection. Convenience sampling results are difficult to repeat, and the current study's findings are not applicable to the whole population. The Chinese government recently announced the "Internet Plus Exercise" policy for active living and wellbeing. In the light of our study findings, future research can be conducted to assess the impact of Chinese government policy "Internet Plus Exercise," which can be a fascinating future research scope of the current study.

\section{Abbreviations}

PC, portable computer; PTSD, post-traumatic stress disorder; ADHD, attention-deficit/hyperactivity disorder; VRET, virtual reality exposure therapy; VR, virtual reality.

\section{Acknowledgments}

We thank the participants for participating in this research and making this study possible.

\section{Funding}

This paper belongs to the project "Study on residents' Participation in Sports Activities in Kunshan City." The project funding number is AS10601020; 2019-2021.

\section{Disclosure}

The authors report no conflicts of interest in this work.

\section{References}

1. Virtual reality. Cambridge Dictionary. Available from: https://diction ary.cambridge.org/dictionary/english/virtual-reality. Accessed Nove mber 13, 2021

2. Valmaggia LR, Latif L, Kempton MJ, Rus-Calafell M. Virtual reality in the psychological treatment for Mental Health Problems: an systematic review of recent evidence. Psychiatry Res. 2016;236:189-195. doi:10.1016/j.psychres.2016.01.015

3. Jerdan SW, Grindle M, van Woerden HC, Kamel Boulos MN. Headmounted virtual reality and mental health: critical review of current research. JMIR Serious Games. 2018;6(3):e14. doi:10.2196/ games. 9226

4. Parsons TD, Courtney CG, Dawson ME. Virtual reality stroop task for assessment of supervisory attentional processing. J Clin Exp Neuropsychol. 2013;35(8):812-826. doi:10.1080/13803395.201 3.824556

5. Slater M. Presence and emotions. CyberPsychology and Behavior. 2004;7(1):121. doi:10.1089/109493104322820200

6. Rizzo AS, Kim GJ. A SWOT analysis of the field of virtual reality rehabilitation and therapy. Presence. 2005;14(2):119-146. doi: $10.1162 / 1054746053967094$

7. Zeng N, Pope Z, Lee J, Gao Z. Virtual reality exercise for anxiety and depression: a preliminary review of current research in an emerging field. J Clin Med. 2018;7(3):42. doi:10.3390/jcm7030042 
8. Ryu J-H, Park J-W, Nahm F, et al. The effect of gamification through a virtual reality on preoperative anxiety in pediatric patients undergoing general anesthesia: a prospective, randomized, and controlled trial. J Clin Med. 2018;7(9):284. doi:10.3390/jcm7090284

9. Langarizadeh M, Tabatabaei M, Tavakol K, Naghipour M, Moghbeli F. Telemental health care, an effective alternative to conventional mental care: a systematic review. Acta Informatica Medica. 2017;25(4):240. doi:10.5455/aim.2017.25.240-246

10. Karyotaki E, van Ballegooijen W. Digital self-help interventions for suicidal ideation and behaviour. Lancet Digital Health. 2020;2 (1):30215-30218.

11. Yim SH, Schmidt U. Experiences of computer-based and conventional self-help interventions for eating disorders: a systematic review and meta-synthesis of qualitative research. Int $J$ Eating Disorders. 2019;52(10):1108-1124. doi:10.1002/eat.23142

12. Riva G, Wiederhold BK. How cyberpsychology and virtual reality can help us to overcome the psychological burden of coronavirus. Cyberpsychol Behav Soc Netw. 2020;23(5):277-279. doi:10.1089/ cyber.2020.29183.gri

13. Srivastav AK, Samuel AJ. E-rehabilitation: one solution for patients with Parkinson's disease in covid-19 ERA. Parkinsonism Relat Disord. 2020;75:128-129. doi:10.1016/j.parkreldis.2020.05.021

14. Deutsch JE, Westcott McCoy S. Virtual reality and serious games in neurorehabilitation of children and adults: prevention, plasticity, and participation. Pediatric Phys Therapy. 2017;29(1):29. doi:10.1097/ pep.0000000000000387

15. WHO. COVID-19 transmission and protective measures| who western pacific. Available from: https://www.who.int/westernpacific/emer gencies/covid-19/information/transmission-protective-measures. Accessed December 16, 2021.

16. WHO. Advice for the public on COVID-19. Available from: https:// www.who.int/emergencies/diseases/novel-coronavirus-2019/advicefor-public. Accessed December 16, 2021.

17. Shah SG, Nogueras D, van Woerden HC, Kiparoglou V. The COVID-19 pandemic: a pandemic of lockdown loneliness and the role of Digital Technology. J Med Internet Res. 2020;22(11):e22287. doi:10.2196/22287

18. Srivastav A, Samuel A. E-neurorehabilitation: use of mobile phone based health applications during the COVID-19 pandemic. J Rehabil Med. 2020;52(9):jrm00099. doi:10.2340/16501977-2734

19. Smith L, Jacob L, Yakkundi A, et al. Correlates of symptoms of anxiety and depression and mental wellbeing associated with covid-19: a cross-sectional study of UK-based respondents. Psychiatry Res. 2020;291:113138. doi:10.1016/j.psychres.202 0.113138

20. Troyer EA, Kohn JN, Hong S. Are we facing a crashing wave of neuropsychiatric sequelae of covid-19? Neuropsychiatric symptoms and potential immunologic mechanisms. Brain Behav Immun. 2020;87:34-39. doi:10.1016/j.bbi.2020.04.027

21. Rogers JP, Chesney E, Oliver D, et al. Psychiatric and neuropsychiatric presentations associated with severe coronavirus infections: a systematic review and meta-analysis with comparison to the COVID-19 pandemic. Lancet Psychiatry. 2020;7(7):611-627. doi:10.1016/s2215-0366(20)30203-0

22. Kazdin AE. Encyclopedia of Psychology. Washington, DC, USA: Oxford University Press; 2000.

23. Khan S, Siddique R, Li H, et al. Impact of coronavirus outbreak on Psychological Health. J Glob Health. 2020;10(1). doi:10.7189/ jogh.10.010331

24. Torales J, O’Higgins M, Castaldelli-Maia JM, Ventriglio A. The outbreak of covid-19 coronavirus and its impact on Global Mental Health. Int J Soc Psychiatry. 2020;66(4):317-320. doi:10.1177/ 0020764020915212

25. Thomala LL Fitness industry in China. Statista. Available from: https://de.statista.com/themen/5310/fitness-industry-in-china/. Accessed December 16, 2021
26. Riva G, Bernardelli L, Castelnuovo G, et al. A virtual reality-based self-help intervention for dealing with the psychological distress associated with the COVID-19 lockdown: an effectiveness study with a two-week follow-up. Int $J$ Environ Res Public Health. 2021;18(15):8188. doi:10.3390/ijerph18158188

27. Mestre DR, Dagonneau V, Mercier C-S. Does virtual reality enhance exercise performance, enjoyment, and dissociation? An exploratory study on a stationary bike apparatus. Presence. 2011;20(1):1-14. doi: 10.1162 /pres a 00031

28. Lovett L VR could be key to helping recovered COVID-19 patients get therapy, according to experts. MobiHealthNews. Available from: https://www.mobihealthnews.com/news/vr-could-be-key-helpingrecovered-covid-19-patients-get-therapy-according-experts. 2020. Accessed December 14, 2021.

29. Cigna 2020 Loneliness Report - Cigna Official Site. Available from: https://www.cigna.com/static/www-cigna-com/docs/about-us/news room/studies-and-reports/combatting-loneliness/cigna-2020loneliness-report.pdf. Accessed November 13, 2021.

30. Miller ED, Miller ED. Loneliness in the era of covid-19. Front Psychol. 2020;11. doi:10.3389/fpsyg.2020.02219

31. Tate EB, Spruijt-Metz D, O'Reilly G, et al. Mhealth approaches to Child obesity prevention: successes, unique challenges, and next directions. Transl Behav Med. 2013;3(4):406-415. doi:10.1007/ s13142-013-0222-3

32. Opriş D, Pintea S, García-Palacios A, Botella C, Szamosközi S, David D. Virtual reality exposure therapy in anxiety disorders: a quantitative meta-analysis. Depress Anxiety. 2011;29(2):85-93. doi:10.1002/da.20910

33. Imam B, Jarus T. Virtual reality rehabilitation from social cognitive and motor learning theoretical perspectives in stroke population. Rehabil Res Pract. 2014;2014:1-11. doi:10.1155/2014/594540

34. Juras G, Brachman A, Michalska J, et al. Standards of virtual reality application in balance training programs in clinical practice: a systematic review. Games Health J. 2019;8(2):101-111. doi: $10.1089 / \mathrm{g} 4 \mathrm{~h} .2018 .0034$

35. WHO. Stay physically active during self-quarantine. World Health Organization. Available from: https://www.euro.who.int/en/healthtopics/health-emergencies/coronavirus-covid-19/publications-andtechnical-guidance/noncommunicable-diseases/stay-physically-active -during-self-quarantine. Accessed November 11, 2021.

36. Conroy DE, Yang C-H, Maher JP. Behavior change techniques in top-ranked mobile apps for physical activity. Am J Prev Med. 2014;46(6):649-652. doi:10.1016/j.amepre.2014.01.010

37. Urbach N, Ahlemann F. Structural equation modeling in information systems research using partial least squares. J Information Tech Theory Appl. 2010;11(2):5-40.

38. Nunnally JC. Psychometric Theory 3E. Tata McGraw-hill education; 1994.

39. Campbell DT, Fiske DW. Convergent and discriminant validation by the multitrait-multimethod matrix. Psychol Bull. 1959;56(2):81. doi: $10.1037 / \mathrm{h} 0046016$

40. Connelly J, Kirk A, Masthoff J, MacRury S. The use of technology to promote physical activity in type 2 diabetes management: a systematic review. Diabetic Med. 2013;30(12):1420-1432. doi:10.1111/ dme. 12289

41. Vieira GD, Araujo DF, Leite MA, Orsini M, Correa CL. Realidade virtual na reabilitação física de pacientes com doença de Parkinson. J Human Growth Dev. 2014;24(1):31. doi:10.7322/jhgd.72046

42. Pasco D. The potential of using virtual reality technology in physical activity settings. Quest. 2013;65(4):429-441. doi:10.1080/ 00336297.2013 .795906

43. Brooks SK, Webster RK, Smith LE, et al. The psychological impact of quarantine and how to reduce it: rapid review of the evidence. Lancet. 2020;395(10227):912-920. doi:10.1016/s0140-6736(20) 30460-8 
44. Picard RW. Automating the recognition of stress and emotion: from lab to real-world impact. IEEE MultiMedia. 2016;23(3):3-7. doi:10.1109/mmul.2016.38

45. Holden RJ, Karsh B-T. The Technology Acceptance Model: its Past and its future in Health Care. J Biomed Inform. 2010;43(1):159-172. doi:10.1016/j.jbi.2009.07.002

46. Siani A, Marley SA. Impact of the recreational use of virtual reality on physical and mental wellbeing during the COVID-19 lockdown. Health Technol. 2021;11(2):425-435. doi:10.1007/s12553-02100528-8

47. Matias T, Dominski FH, Marks DF. Human needs in COVID-19 isolation. $J$ Health Psychol. 2020;25(7):871-882. doi:10.1177/ 1359105320925149

48. Zhou S. Using virtual reality to promote physical activity. J Software Eng Appl. 2020;13(11):312-326. doi:10.4236/jsea.2020.1311021

49. Taylor N. Challenges in measuring physical activity in the context of mental health. Phys Activity Mental Health. 2014. doi:10.5040/ 9781492595724.ch-003

50. Salmon P. Effects of physical exercise on anxiety, depression, and sensitivity to stress. Clin Psychol Rev. 2001;21(1):33-61. doi:10.1016/s0272-7358(99)00032-x

51. Vigo D, Thornicroft G, Atun R. Estimating the true global burden of mental illness. Lancet Psychiatry. 2016;3(2):171-178. doi:10.1016/ s2215-0366(15)00505-2
52. Torous J, Bucci S, Bell IH, et al. The growing field of digital psychiatry: current evidence and the future of apps, social media, Chatbots, and virtual reality. World Psychiatry. 2021;20(3):318-335. doi:10.1002/wps.20883

53. Mestre DR, Dagonneau V, Mercier C-S. Does virtual reality enhance exercise performance, enjoyment, and dissociation? An exploratory study on a stationary bike apparatus. Presence. 2011;20(1):1-14. doi:10.1162/pres_a_00031

54. Wiederhold BK, Jang DP, Gevirtz RG, Kim SI, Kim IY, Wiederhold MD. The treatment of fear of flying: a controlled study of imaginal and virtual reality graded exposure therapy. IEEE Trans Information Tech Biomed. 2002;6(3):218-223. doi:10.1109/ titb. 2002.802378

55. WHO. Substantial investment needed to avert mental health crisis. Available from: https://www.who.int/news/item/14-05-2020substantial-investment-needed-to-avert-mental-health-crisis. Accessed December 15, 2021.

56. McCann RA, Armstrong CM, Skopp NA, et al. Virtual reality exposure therapy for the treatment of anxiety disorders: an evaluation of research quality. J Anxiety Disord. 2014;28(6):625-631. doi:10.1016/ j.janxdis.2014.05.010
Psychology Research and Behavior Management

\section{Publish your work in this journal}

Psychology Research and Behavior Management is an international, peer-reviewed, open access journal focusing on the science of psychology and its application in behavior management to develop improved outcomes in the clinical, educational, sports and business arenas. Specific topics covered in the journal include: Neuroscience, memory and decision making; Behavior modification and management; Clinical

\section{Dovepress}

applications; Business and sports performance management; Social and developmental studies; Animal studies. The manuscript management system is completely online and includes a very quick and fair peer-review system, which is all easy to use. Visit http://www. dovepress.com/testimonials.php to read real quotes from published authors. 